\title{
An evaluation method of reliability indicators of automobile textile materials
}

\author{
Liubov Lisienkova ${ }^{1 *}$ \\ ${ }^{1}$ Moscow State University of Civil Engineering, Yaroslavskoe shosse, 26, Moscow, 129337, Russia
}

\begin{abstract}
The aim of the study was to develop a method for predicting the reliability indicators of automobile textile materials. The characteristics of material deformation under conditions of cyclic compression have been studied, the parameters and test modes have been determined. The design and construct of a device for cyclic compression have been shown as well as a method for evaluation of deformation indicators of materials. The results of experimental tests of material samples have been described. As a result, a full-fledged methodology for estimating reliability indicators has been developed. As an evaluation criterion, the change in the deformation of materials during cyclic compression has been selected. The method of cyclic compression has been justified to allow predicting the behaviour of materials in the production and product exploitation.
\end{abstract}

\section{Introduction}

Textile materials are more often used in the cars and automobile production. Automobile textiles are considered as one of the priority areas for development on the upholstery textile market. The range of automotive materials is constantly updated and expanded [1] due to new technologies and compositions. Such textile materials as fabrics, knitted fabrics with various surface, non-woven and complex materials of various structures and composition of substance are widely used.

Materials used for car upholstery are exposed to various mechanical forces, temperature, moisture, insolation during production as well as usage. The car interior materials face compressive forces during exploitation when a passenger sits, leans, leans against. The impact of compressive forces is constantly repeated during exploitation and leads to a change in the size and shape of materials, affects the quality characteristics of the car interior: manufacturability, reliability, and ergonomics. The magnitude of force pressure on materials during production and exploitation varies significantly [2] and reaches 0.01-10 $\mathrm{MPa}$.

It has been proved [3-5] that the deformation conditions affect the mechanism of structural rearrangement and the properties of materials. The change in the structure of materials during compression affects its geometric, mechanical, physical properties. While under external compressive force the materials basically retain their integrity their shape, щи the contrary, changes.

\footnotetext{
* Corresponding author: lisienkovaln@mail.ru
} 
Known methods and tools basically allow to define semi- and one-cycle characteristics of materials properties at compression and do not reflect the behavior of materials under conditions simulating exploitation ones. A promising method has been described in - it allows evaluating the deformation effect of compression forces on the material, where deformation is defined as a function of the specific pressure. However, this method is practically not implemented. For evaluating the properties of materials during compression the hardness index of materials can also be applied in accordance with state standards GOST 263-75 and GOST 20403-75. Another type of evaluation methods (hardness evaluation ones) are suitable for studying the properties of materials of monolithic structures with a thickness of at least $6 \mathrm{~mm}$.

Comparing to textile materials for clothing and footwear where the deformation such materials is studied on profound level, deformation of materials for car interior upholstery has not been studied enough. There are no systematic studies of the properties of such materials under compression. The variety of textile materials for automobile purposes leads to the complication of materials selection in car manufacturing and requires the development of objective and unified methods for monitoring materials quality.

The main drawback of existing methods and tools is that they are based on single-cycle static deformation. The conditions for materials testing do not allow evaluating the influence of factors of production and exploitation of the material on its structure.

The problem is that modern methods do not allow evaluating the behavior of materials of different structure and properties under production and exploitation conditions.

The purpose of the work is to develop a method and tools for evaluating the deformation of materials under conditions of cyclic compression to predict their behavior during production and exploitation.

\section{Methodical support and research objects description}

Within the study a device for material compression has been developed (Figure 1), which includes: a steel container of cylindrical shape (3) for locating a sample (1) and a removable indenter (4) in which between the base and the working area a layer of microporous rubber is placed to ensure even pressure on the sample.

A distinctive feature of the developed methods and means [6-11] is the ability to model conditions close to real production and exploitation: the creation of a constrained or free cyclic compression, wet, liquid or other external environments inside the container (3) (Figure 1) during testing or stable state of a sample.

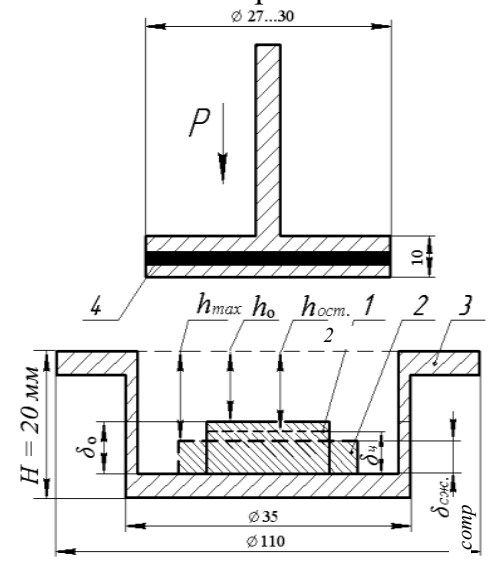

Fig. 1. Material compression scheme (1 - a sample before compression; 2 - a sample while compression; 3 - a container for a sample placement; 4 - indenter 
The absence of measuring instrument pressure on the sample ensures the objectivity of the results of thickness estimation, which is important in the study of the fibrous materials properties. The usage of differential photodetectors as a part of the measuring system of a device makes it possible to measure the thickness of a sample in a non-contact way without changing the position of a sample what ensures the accuracy of the measurements.

Sample thickness before compression

$$
\delta_{0}=H-h_{0},
$$

where $H$ is the depth of a container for a sample placement $(H=20 \mathrm{~mm})$;

$h_{0}$ is a value of a measurer shift before sample compression, $\mathrm{mm}$.

Sample thickness during compression

$$
\delta_{1}=H-h_{\max },
$$

where $h_{\max }$ is a value of an indenter shift during compression, mm.

Sample thickness after compression

$$
\delta_{2}=H-h_{2},
$$

where $h_{2}$ is a value of measurer shift after compression, mm.

The pressure on the sample is carried out by an external load of 0.01-4.0 daN transmitted through the indenter with a diameter of 10-30 mm. For materials with thickness $0.1-20 \mathrm{~mm}$ in the conditions of constrained compression the diameter of the sample $\mathrm{d} 1 \mathrm{is} 30 \mathrm{~mm}$, in the conditions of free compression $-\mathrm{d} 2 \leq 25 \mathrm{~mm}$.

Previously [12] the optimum compression parameters were experimentally established: the working dimensions of the indenter are $30 \mathrm{~mm}$, the samples are $15-30 \mathrm{~mm}$; the loading and resting time of the sample in a cycle of 5-30 s, the pressure on the sample is 0.01-4.0 $\mathrm{kPa}$. The relative random error was $3-12 \%$ for materials with a thickness of $0.1-20.0 \mathrm{~mm}$ at a $10 \%$ significance level in the test with the number of 10 samples.

Preparation of sample materials and tests were carried out in accordance with state standards GOST 10681, GOST 12023, GOST 20566, GOST 8.207 GSI, GOST 8844. The characteristics of the objects are presented in Table. 1.

To simulate external influences on samples of materials differing in composition and production methods they were preliminary moistened in a steam-air environment up to $30 \%$

\begin{tabular}{|c|c|c|c|}
\hline Name & $\begin{array}{c}\text { Fibrous } \\
\text { composition, } \%\end{array}$ & $\begin{array}{l}\text { Surface density, } \\
\mathrm{g} / \mathrm{m}^{2}\end{array}$ & $\begin{array}{c}\text { Thickness, } \\
\mathrm{mm}\end{array}$ \\
\hline 1.Stitched cotton canvas, code 917618 & Co-100 & 250,0 & 5,1 \\
\hline 2. Half-wool canvas, code 927622 & $\begin{array}{l}\text { WO-85 } \\
\text { PL-15 }\end{array}$ & 200,0 & 6,1 \\
\hline $\begin{array}{l}\text { 3. Non-woven fabric of synthetic fibers, code } \\
\text { CK } 150 / 300\end{array}$ & PL-100 & 140,0 & 12,1 \\
\hline 4. Non-woven fabric & PL-100 & 130,0 & 12,0 \\
\hline 5. Half-wool blend fabric, vendor code 4514 & $\begin{array}{l}\text { WO-67 } \\
\text { PAN-33 }\end{array}$ & 560,0 & 3,1 \\
\hline 6. Woollen velour, vendor code 3655 & WO-100 & 650,0 & 5,6 \\
\hline 7. Lint knitted canvas & $\begin{array}{l}\text { PL-50 } \\
\text { VI-50 }\end{array}$ & 261,0 & 1,2 \\
\hline 8. Electro floated non-woven wireframe fabric & $\begin{array}{l}\text { Co-23, PL-30, } \\
\text { PAN-47 }\end{array}$ & 325,0 & 2,7 \\
\hline
\end{tabular}
and subsequently compression at a pressure of $0.2-0.5 \mathrm{kPa}$ pre cycle.

Table 1. Materials characteristics. 


\section{Experimental studies of the deformation of materials under conditions of cyclic compression}

In this section the properties of materials under cyclic compression conditions are presented as a conclusion of materials samples tests in the condensing state and after preliminary moistening in a steam-air environment up to $30 \%$. As a result set of calculated indicators allows predicting the qualitative characteristics of materials during production and exploitation.

The materials have been examined by a method of cyclic compression with the following test parameters: the compression number cycles 50-100, the compression and rest time for a sample is 5 seconds per cycle, a cyclic load is $1.5 \mathrm{daN}$; diameter of the sample with constrained compression $\mathrm{d} 1=30 \mathrm{~mm}$, with free compression $\mathrm{d} 2=20 \mathrm{~mm}$; diameter of the indenter $\mathrm{D}=30 \mathrm{~mm}$. The pressure on the sample was $0.5 \mathrm{kPa}$ at free compression and 0.2 $\mathrm{kPa}$ at constrained compression. The relative measurement error was $1.5-8.4 \%$.

The graphs of a measurer shift after 100 compression cycles have been built - Fig. 2a, b for constrained and free compression correspondingly before test; Fig. 2c, d for constrained and free compression correspondingly after samples humidification in a steam-air environment of $30 \%$.

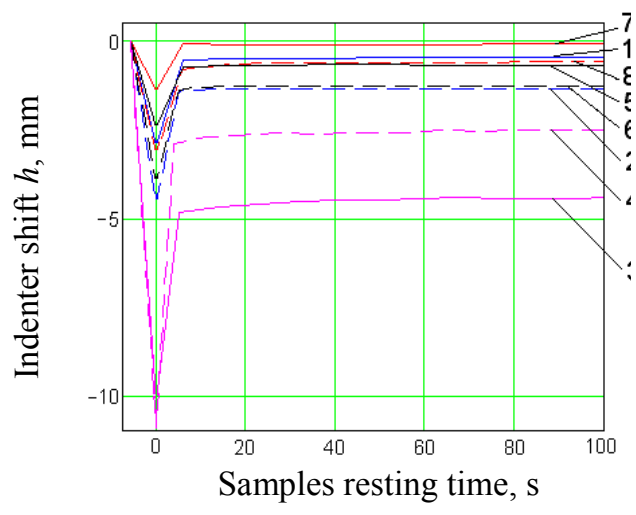

a)

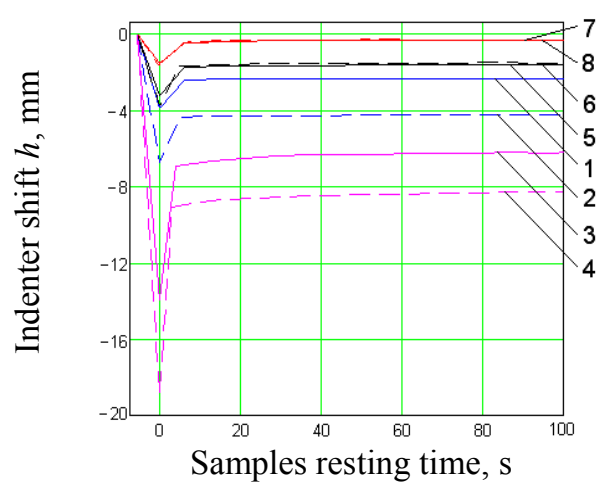

c)

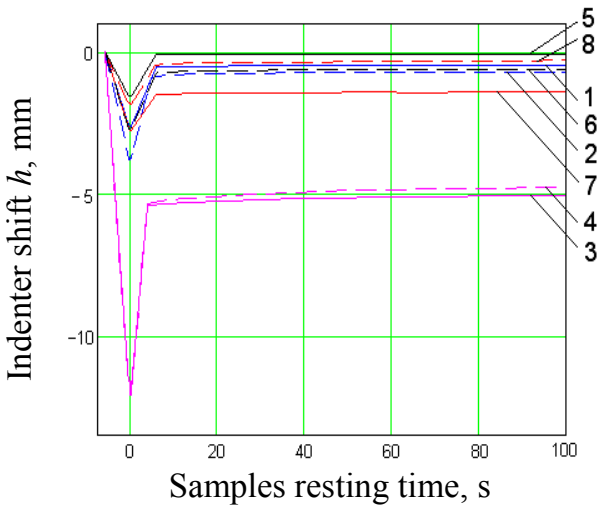

b)

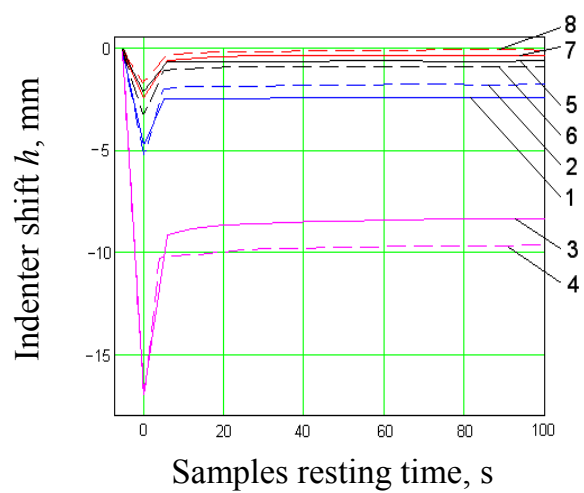

d)

Fig. 2. Experimental graphs of intender shift after 100 cycles of sample compression and rest: a, c constrained compression; $b, d$ - free compression ( $c, d-$ after sample humidification). Samples: 1 stitched cotton canvas, 2 - half-wool canvas; 3 - non-woven fabric of synthetic fibers; 4 - non-woven fabric; 5 - half-wool blend fabric; 6 - woolen velour; 7 - lint knitted canvas; 8 - electro floated nonwoven wireframe fabric 
A comparative analysis of the results has shown that with constrained compression of samples in normal state a decrease in thickness is less than in constrained compression of samples moistened in a vapor-air environment. The greatest reduction in thickness $(20-45 \%)$ in the humidified state after 100 cycles of constrained compression is typical for materials that contain natural fibers (samples 1, 2, 5,6) as well as for bulk nonwoven webs (samples $3,4)$. A smaller change in thickness after compression has materials with chemical fibers, stronger bonds (weaving, gluing) of structural elements (samples 7, 8). With free compression the thickness is generally greater for all materials compared to similar results for constrained compression which can be explained by the test parameters.

\section{Analysis of experimental studies results}

Figure 3 illustrates the results of material deformation after compression. It has been established that the reduction in materials thickness under free compression is greater that under constrained compression. Thus reversible deformation in the constrained and free compression of materials is greater without preliminary humidification and similar actions (Fig. 3). Analysis of the results has shown that after 100 cycles of constrained compression in humidified state materials that contain natural fibres (samples 1, 2, 5, 6) have the largest value of non-reversible deformation (30-45\%) due to the structure morphology and frictional force between the fibres. The same is true for bulk sheets (samples 3,4) where the initial structural bonds change under steaming and further compression. More resistant to compression in the wet state is an electro floated non-woven fabric (sample 8).

Furthermore the results have shown that the reversible deformation of samples after humidification and 100 cycles of free compression (Figure 3, samples 2, 5,6) is greater than in the case of constrained compression. It is also established that the magnitude and dynamics of the the deformation of materials during cyclic compression depend on the composition, structure, climatic and environmental conditions and parameters of the test.

Generally the magnitude of reversible deformation (5.0-25\%) in constrained and free compression is greater with the absence of preliminary humidification in the vapour-air environment. Thus, the properties of materials under compression depend on many factors; the most important are the form of the polymer material, the structure and compression conditions.

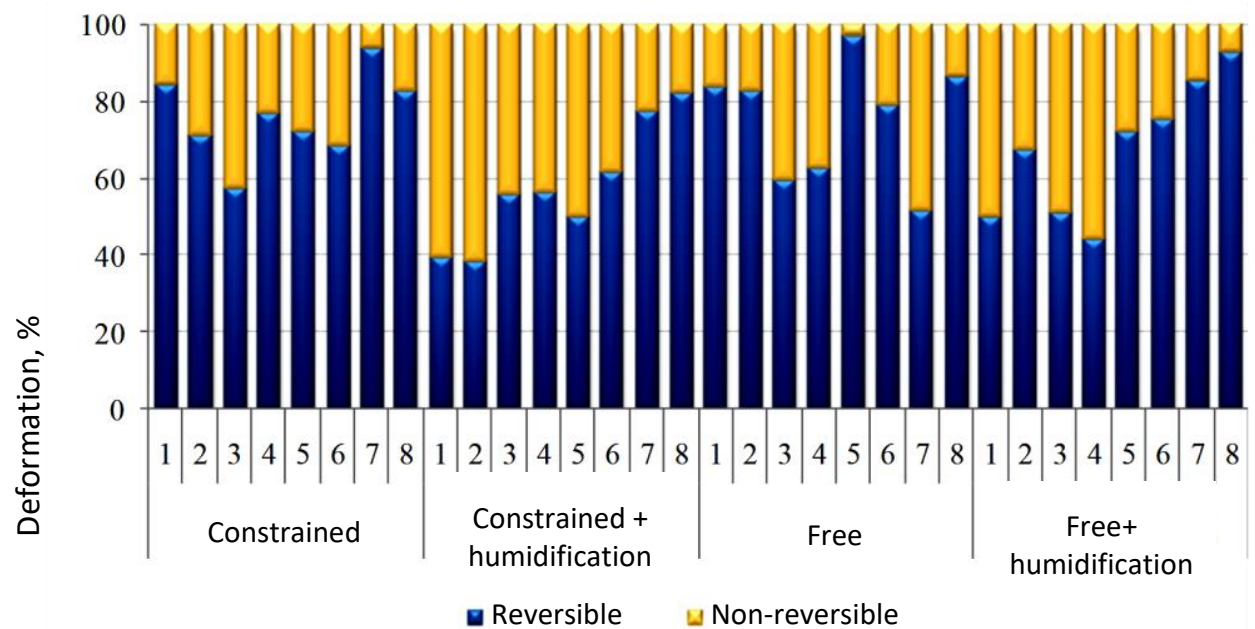

Fig.3. Material deformation after 100 compression cycles. Samples: 1 - stitched cotton canvas, 2 half-wool canvas; 3 - non-woven fabric of synthetic fibers; 4 - non-woven fabric; 5 - half-wool blend fabric; 6 - woolen velour; 7 - lint knitted canvas; 8 - electro floated non-woven wireframe fabric. 


\section{Development of a method for predicting material reliability indicators}

A method of complex evaluation of moldability and form stability of objects and materials under cyclic compression has been developed, as a basis the analysis of following compressibility indices has been chosen: the indices of initial and residual compressibility.

The index of initial compressibility characterizes the properties of the material under conditions simulating effects of technological factors and predicts the choice of design and methods of technological processing:

$$
K_{\text {comp }}=C_{2} / C_{l} \text {, }
$$

where $\mathrm{C} 1$ and $\mathrm{C} 2$ are the compressibility values determined by the total strain (\%) value for a single cycle of free sample compression in the normal and humidified state correspondingly. The compressibility factor $\mathrm{C} 2$ is determined by the formula (4) for samples in the humidified state. A comparative evaluation of the properties of different materials can be carried out using the index of initial compressibility of materials in the humidified state.

The compressibility indices $\mathrm{C} 1$ and $\mathrm{C} 2$ are determined by the formula:

$$
C_{i}=100\left(\delta_{0}-\delta_{\text {comp }}\right) / \delta_{0},
$$

where $\delta_{0}-\delta_{\text {comp }}$ is the sample thickness in normal (or humidified) state before and after compression respectively, mm. It follows from formulas (4) and (5) that the larger $K_{\text {сж }}\left(K_{\text {сж }}\right.$ $>1$ ) the better the molding properties of materials under pressure and humidification.

The residual cyclic compressibility index is determined by the residual strain (\%) after 50 ... 100 compression cycles on the sample:

$$
C_{\text {cyclic }}=\varepsilon_{\text {residual }}=\left(\delta_{0}-\delta_{\text {cyclic }}\right) / \Delta h_{\text {comp }},
$$

where $\delta_{\text {cyclic }}$ is the thickness of a sample after the compression cycles, $\mathrm{mm}$.

Absolute total deformation of a sample during cyclic compression $(\mathrm{mm})$

$$
\Delta h_{\text {comp }}=\delta_{0}-\delta_{\text {comp }} \text {. }
$$

The residual compressibility index $C_{\text {cyclic }}$ can be determined by varying the test conditions: constrained or free compression, normal or humidified state of samples, with preliminary processing of samples (pressing, duplication, wet-heat effects). The indicator $C_{c y c l i c}$ characterizes properties of materials after cyclic compression which simulates exploitation conditions and predicts reliability indicators of products (form stability, size change). The analysis of $K_{\text {comp }}$ and $C_{c y c l i c}$ indicators can provide a complex evaluation of the changes in material under conditions of cyclic compression which simulate conditions of production and exploitation as well as predict the behavior of materials at the stages of the product life cycle. To assess the moldability and form stability a material grading in terms of indices of initial and residual compressibility for single and multiple compression has been developed. The materials are divided into three groups according to the index of their initial compressibility $K_{\text {comp }}$ : the first $(>0,8)$, the second $(0,6 \ldots 0,7)$, the third $(<0,6)$. Also the materials are divided into three groups according to the cyclic (residual) compressibility parameter $C_{\text {cyclic }}, \%$ : the first ( $\left.2 \ldots 20\right)$, the second $(21 \ldots 40)$, the third ( $\left.>40\right)$.

Practical recommendations on the reasonable choice of materials for products, design and methods of technological processing of products based on the results of a complex evaluation of the materials compressibility have been developed. A supportive paper on the material deformation under conditions of cyclic compression for reasonable choice of materials has been developed. 


\section{Conclusion}

The objective indicators for predicting the material reliability during the exploitation have been proposed. They are reversible and non-reversible material deformation under cyclic compression. A method and means of cyclic compression which allow studying the dynamics of the change in the material deformation under simulating production and exploitation factors have been developed. The mechanism of the change in the material deformation under conditions of cyclic compression has been studied.

A developed method of cyclic compression has the following advantages: high measurement accuracy, the suitability for both constrained and free compression under the additional forces of external factors (moisture, heat). A methodology for the complex evaluation of the material compressibility has been developed, compressibility indices have been proposed for prediction of the material reliability. A comprehensive analysis of the indices increases the objectivity of material properties evaluation and makes it possible to predict the reliability of products in the process of production and further exploitation.

In an article [13] it has been shown that a developed method is considered promising for studying the changes in the thermophysical material properties under conditions of cyclic compression.

\section{References}

1. I. Mustaev, PhD thesis (1999)

2. A. Zhikharev, $\mathrm{PhD}$ thesis (2005)

3. L. Lisienkova, E. Shitlina, Izvestiya Vysshikh Uchebnykh Zavedenii, Seriya Teknologiya Tekstil'noi Promyshlennosti, 24-28 (2009)

4. L. Lisienkova, A. Deryabina, Problematyczne aspekty i rozwiązania we współczesnej nauce, 6-10 (2012)

5. L. Lisienkova, Izvestiya Vysshikh Uchebnykh Zavedenii, Seriya Teknologiya Tekstil'noi Promyshlennosti, 6-8 (2009)

6. L. Lisienkova, E. Kirsanova, Izvestiya Vysshikh Uchebnykh Zavedenii, Seriya Teknologiya Tekstil'noi Promyshlennosti, 15-18 (2010)

7. L. Lisienkova, E. Baranova, V. Stelmaschenko, A. Salamatin, Patent № 2354953 C2 Russian Federation, IPC G01N 3/08 Device for determining the deformation properties of leather and similar flexible materials, 2009

8. L. Lisienkova, E. Baranova, V. Stelmaschenko, A. Salamatin, Patent for utility model Russian Federation № 144579 U1, MPK G01N 3/08 Device for determining the deformation of textile materials under compression, 2014

9. L. Lisienkova, A. Deryabina, O. Tarasova, Izvestiya Vysshikh Uchebnykh Zavedenii, Seriya Teknologiya Tekstil'noi Promyshlennosti, 29-34 (2015)

10. L. Lisienkova, O. Smolina, Izvestiya Vysshikh Uchebnykh Zavedenii, Seriya Teknologiya Tekstil'noi Promyshlennosti, 163-155 (2016)

11. L. Lisienkova, A. Deryabina, Izvestiya Vysshikh Uchebnykh Zavedenii, Seriya Teknologiya Tekstil'noi Promyshlennosti, 32-36 (2013)

12. L. Lisienkova, $\mathrm{PhD}$ thesis (in Russian), 269 (2010)

13. L. Lisienkova, A. Deryabina, Izvestiya Vysshikh Uchebnykh Zavedenii, Seriya Teknologiya Tekstil'noi Promyshlennosti, 94-98 (2016) 